\title{
Growth inhibitory efficacy of the nutritional herb Psoralea corylifolia in a model of triple-negative breast cancer
}

\author{
NITIN T. TELANG ${ }^{1}$, HAREESH B. NAIR ${ }^{2}$ and GEORGE Y.C. WONG ${ }^{3,4}$ \\ ${ }^{1}$ Cancer Prevention Research Program, Palindrome Liaisons Consultants, Montvale, NJ 07645-1559; ${ }^{2}$ Department of \\ Obstetrics and Gynecology, University of Texas Health Sciences Center, San Antonio, TX 78229; ${ }^{3}$ American Foundation \\ for Chinese Medicine, New York, NY 10001; ${ }^{4}$ Breast Center, Maimonides Medical Center, Brooklyn, NY 11220, USA
}

Received April 13, 2021; Accepted July 5, 2021

DOI: $10.3892 /$ ijfn.2021.18

\begin{abstract}
Triple-negative breast cancer (TNBC) lacks the expression of estrogen receptor- $\alpha$ (ER- $\alpha)$, progesterone receptor (PR) and amplified human epidermal growth factor receptor-2 (HER-2). Current treatments involve chemotherapy and molecular targeted therapy. These options lead to dose-limiting systemic toxicity and acquired tumor resistance. Moreover, no drug is yet available for the secondary prevention of TNBC. Such limitations underscore a need to investigate non-toxic testable alternatives for the secondary prevention/treatment of TNBC. The Chinese nutritional herb, Psoralea corylifolia (PC), has been shown to be effective against the MCF-7 cell line, a cellular model for ER- $\alpha$-positive breast cancer. The present study aimed to investigate the growth inhibitory effects of PC against TNBC using the MDA-MB-231 cell line. Anchorage-independent colony formation, cell cycle progression, cellular apoptosis, RB signaling and caspase-3/7 activity assays were performed to determine the quantitative parameters for the efficacy of $\mathrm{PC}$. Treatment with PC induced a 3.5-fold increase in the $\mathrm{G}_{1}: \mathrm{S}+\mathrm{G}_{2} / \mathrm{M}$ ratio, an 11-fold increase in the apoptotic cell number and a 149-fold increase in caspase-3/7 activity. PC treatment also decreased cyclin D1, CDK4/6 and p-RB expression levels. On the whole, the data of the present study identify mechanistic leads for PC as a naturally occurring testable alternative, and validate a mechanistic approach to prioritize efficacious nontoxic herbal extracts as nutritional supplements for the secondary prevention/therapy of TNBC.
\end{abstract}

\section{Introduction}

Conventional treatment options for the triple-negative breast cancer (TNBC) subtype include anthracycline/taxol/

Correspondence to: Professor Nitin T. Telang, Cancer Prevention Research Program, Palindrome Liaisons Consultants, 10 Rolling Ridge Road, Suite B, Montvale, NJ 07645-1559, USA

E-mail: ntelang3@gmail.com

Key words: triple-negative breast cancer, growth inhibition, cellular apoptosis, nutritional herb platinum-based conventional cytotoxic therapy or phosphoinositol-3-kinase (PI3K), AKT, molecular target of rapamycin (mTOR) and poly(ADP-ribose) polymerase (PARP) selective small molecule based targeted therapy (1-3). These long-term treatment options are frequently associated with systemic toxicity and acquired drug resistance, leading to the progression of therapy-resistant disease (4). At present, no drug is yet available for the secondary prevention of TNBC, at least to the best of our knowledge. These therapeutic limitations emphasize the need for the identification of non-toxic efficacious agents as testable alternatives against TNBC.

Natural products, including dietary and medicinal phytochemicals, botanicals and nutritional herbs have documented preventative/therapeutic/efficacy in complementary and alternative medicine against breast cancer subtypes $(5,6)$. These naturally occurring compounds may represent effective dietary supplements for the prevention/therapy of organ site cancers. Several mechanistically distinct Chinese nutritional herbs have been demonstrated to exert growth inhibitory effects in cellular models for the estrogen receptor (ER)- $\alpha^{+} /$progesterone receptor $(\mathrm{PR})^{+} /$human epidermal growth factor receptor-2 (HER2)- (Luminal A) and ER- $\alpha^{-} / \mathrm{PR}^{-} / \mathrm{HER}-2^{-}$(triple-negative) molecular subtypes of breast cancer (7-10). Published evidence from a comparative study on isogenic MCF-7 cellular phenotypes with modulated ER- $\alpha$ function demonstrated that the Chinese nutritional herb, Psoralea corylifolia (PC), effectively inhibited growth in the phenotypes with functional or non-functional ER- $\alpha$ (7).

The aim of the present cell culture study was to evaluate the growth inhibitory effects of PC in a cellular model for TNBC and to identify possible mechanistic leads for the efficacy of this nutritional herb. These in vitro data may provide a scientific basis for subsequent in vivo studies on triple-negative tumors. The MDA-MB-231 cellular model of TNBC was selected as the experimental system. The TNBC breast cancer subtype is notable for the compromised tumor suppressive function of the RB gene (11). Thus, the experimental downregulation of the aberrant function of RB may identify potential molecular targets for the efficacy of PC.

\section{Materials and methods}

Experimental model. The MDA-MB-231 cell line is isolated from the pleural effusion of human metastatic breast 
carcinoma. The carcinoma cells lack the expression levels of ER- $\alpha$, PR and amplified HER-2, and represent an experimental model for TNBC $(12,13)$. This cell line was obtained from the American Type Culture Collection (ATCC), and the cells were maintained in RPMI-1640 medium with L-glutamine and $5 \%$ fetal bovine serum (Life Technologies; Thermo Fisher Scientific, Inc.) following the protocol a recommended by ATCC.

Test agent. A non-fractionated aqueous extract of PC was prepared by boiling $20 \mathrm{~g}$ of seeds of PC provided by the author GYCW in $200 \mathrm{ml}$ of deionized distilled water followed by sequential boiling and centrifugation to obtain a concentrated extract at a concentration of $20 \mathrm{~g}$ extract in $20 \mathrm{ml}$ deionized distilled water $(7,8,10)$. This stock solution was subsequently diluted in the culture medium to obtain a concentration of $1 \mathrm{mg}$ extract/1 $\mathrm{ml}$. This diluted stock solution was subsequently used on the cell cultures at the $\mu \mathrm{g} / \mathrm{ml}$ concentration range.

Analysis of dose response effect of $P C$. The dose response effect of PC was determined by examining cell viability using the Cell Titre Glo assay (Promega Corporation) as recommended in the protocol provided by the manufacturer. This assay measures relative luminescent units (RLUs) as a quantitative end point. Briefly, $5.0 \times 10^{3}$ cells were seeded in 96-well plates and treated with $\mathrm{PC}$ at a $1-100 \mu \mathrm{g} / \mathrm{ml}$ concentration range for 6 days at $37^{\circ} \mathrm{C}$ in a $\mathrm{CO}_{2}$ incubator. The medium containing PC was replenished every $72 \mathrm{~h}$. Untreated cultures maintained in the culture medium represented the control. Cell viability was measured on day 7 using a Fluoroskan plate reader (Thermo Fisher Scientific, Inc.), and was expressed as RLUs. The data obtained from the dose response experiment were extrapolated to identify the minimally effective $\left(\mathrm{IC}_{25}\right)$, half maximum $\left(\mathrm{IC}_{50}\right)$ and maximally cytostatic $\left(\mathrm{IC}_{90}\right)$ inhibitory concentrations for the cells treated with PC.

Anchorage-independent (AI) growth assay. This assay was performed following the optimized protocol. Briefly, MDA-MB-231 cell suspensions, at a density of $5 \times 10^{5}$ per $\mathrm{ml}$ prepared in $0.33 \%$ agar with a concentration range of $1-80 \mu \mathrm{g} / \mathrm{ml}$ PC. The untreated cell suspension represented the control. These cell suspensions were overlaid on a basement matrix of $0.6 \%$ agar. The cultures were incubated at $37^{\circ} \mathrm{C}$ in a $\mathrm{CO}_{2}$ incubator for 21 days. The AI colonies were fixed in $4 \%$ phosphate-buffered formaldehyde (cat. no. 100494, Sigma-Aldrich; Merck KGaA, stained with $0.005 \%$ crystal violet (cat. no. C-6158, Sigma-Aldrich; Merck KGaA), overnight at room temperature. The colony counts were determined at x10 magnification. The data were expressed as the AI colony number. These data were extrapolated to identify the $\mathrm{IC}_{25}, \mathrm{IC}_{50}$ and $\mathrm{IC}_{90}$ inhibitory concentrations.

Cell cycle progression assay. For the cell cycle analysis, $5 \times 10^{5}$ cells were seeded in T-25 flasks and treated for $24 \mathrm{~h}$ after seeding with 3,6 and $12 \mu \mathrm{g} / \mathrm{ml}$ of PC for $48 \mathrm{~h}$. The cells were harvested by trypsinization, pelleted at $500 \mathrm{x} \mathrm{g}$, and washed twice with cold PBS. The cells were then fixed with cold $70 \%$ ethanol, washed with cold PBS, and stained with $50 \mu \mathrm{g} / \mathrm{ml}$ propidium iodide in PBS (Sigma-Aldrich; Merck $\mathrm{KGaA}$ ), followed by the addition of $10 \mu \mathrm{g} / \mathrm{ml}$ ribonuclease
(Sigma-Aldrich; Merck $\mathrm{KGaA}$ ), and incubation at $37^{\circ} \mathrm{C}$ for $20 \mathrm{~min}$ and a $4-\mathrm{h}$ incubation of the mixture at $4^{\circ} \mathrm{C}$ in the dark. Cell cycle progression was monitored following an optimized protocol that included the fluorescence-assisted sorting of PI-stained cells, with the use of a $488 \mathrm{~nm}$ excitation filter and a $520 \mathrm{~nm}$ band pass filter, and gating of the sorted cells on a forward versus side scatter. The DNA content was analyzed using a BD FACScan Flow Cytometer (BD Biosciences) and analyzed by FCS Express software version 306 (De Novo Software). The flow cytometry-based analyses determined the distribution of individual cell populations in the $G_{1}$ (quiescent), $\mathrm{S}, \mathrm{G}_{2} / \mathrm{M}$ (proliferative) and sub $\mathrm{G}_{0}$ (apoptotic) phases of the cell cycle. These primary data were expressed as the $\mathrm{G}_{1}: \mathrm{S}+\mathrm{G}_{2} / \mathrm{M}$ ratio and the percentage sub $\mathrm{G}_{0}$ population to assess altered cell cycle progression and cellular apoptosis, respectively.

Western blot analysis. Cells were seeded in 10-cm dishes at $70 \%$ confluence 1 day prior to treatment. Cells were treated with 2, 4 and $6 \mu \mathrm{g} / \mathrm{ml}$ of PC and the cultures were incubated for $48 \mathrm{~h}$ in a $\mathrm{CO}_{2}$ incubator at $37^{\circ} \mathrm{C}$. Cells were harvested and immediately lysed with RIPA buffer containing protease inhibitors (Sigma-Aldrich; Merck KGaA), and centrifuged at $4^{\circ} \mathrm{C}$ for $15 \mathrm{~min}$ at $10,000 \mathrm{x} \mathrm{g}$. The protein content of the lysate was quantified using the Bradford method, and an equal quantity of protein was separated by $10 \%$ SDS-PAGE and transferred onto a nitrocellulose membrane (Bio-Rad Laboratories) and was blocked at $4{ }^{\circ} \mathrm{C}$ overnight with $5 \%$ non-fat dry milk followed by incubation with primary and secondary antibodies (Table I). The chemiluminescent signal was developed with ECL-plus reagent (Bio-Rad, Laboratories, Inc.) and detected by autoradiography. The antibody for $\beta$-actin was used as the reference protein for western blot analysis. The signal intensity in the western blots was quantified as arbitrary scanning units (ASU) using Molecular Imager GS800 and Quantity One software (Bio-Rad Laboratories, Inc.)

Caspase assay. Caspase-3/7 activity in the MDA-MB-231 cells was measured using a Caspase-Glo assay kit (Promega Corporation). Briefly, the cells treated with PC were homogenized by sonication in homogenization buffer $(25 \mathrm{mmol} / \mathrm{l}$ HEPES, pH 7.5, $5 \mathrm{mmol} / 1 \mathrm{MgCl}_{2}$, and $1 \mathrm{mmol} / \mathrm{l} \mathrm{EGTA)}$ and protease inhibitors (all from Sigma-Aldrich; Merck $\mathrm{KGaA}$ ). The homogenate was centrifuged at $6,500 \mathrm{x} \mathrm{g}$ at $4^{\circ} \mathrm{C}$ for $15 \mathrm{~min}$ and the supernatant was used for experiments. To $10 \mu \mathrm{l}$ of the supernatant, equal volume of the assay reagent was added, and the mixture was incubated at room temperature for $2 \mathrm{~h}$. The luminescence was measured using a luminometer (Thermo Fisher Scientific, Inc.). The data were expressed as RLUs.

Statistical analysis. The data were obtained from replicate experiments for the dose response, AI growth, cell cycle progression and caspase-3/7 activity assays and are expressed as the mean $\pm \mathrm{SD}, \mathrm{n}=3$ per treatment group. The comparisons of statistically significant differences between the common control and multiple treatment groups were analyzed using one-way analysis of variance with Dunnett's multiple comparison test as a post-hoc with a threshold of $\alpha=0.05$. $P<0.05$ was considered to indicate a statistically significant difference. 
Table I. Source of antibodies.

\begin{tabular}{lll}
\hline Antibody & \multicolumn{1}{c}{ Vendor } & \multicolumn{1}{c}{ Catalogue no. } \\
\hline Primary & & \\
$\beta$-actin C4 & Santa Cruz Biotechnology, Inc. & sc-47778 \\
Cyclin D1 & Santa Cruz Biotechnology, Inc. & sc-246 \\
RB & Santa Cruz Biotechnology, Inc. & sc-74562 \\
CDK4 & Cell Signaling Technology, Inc. & 12790 \\
CDK6 & Cell Signaling Technology, Inc. & 7961 \\
p-RB Ser780 & Cell Signaling Technology, Inc. & 3590 \\
Secondary & & \\
Anti-rabbit IgG-HRP & Santa Cruz Biotechnology, Inc. & sc-2357 \\
\hline
\end{tabular}

HRP, horseradish peroxidase.

Table II. Growth inhibitory effects of PC on MDA-MB-231 cells.

\begin{tabular}{lcccc}
\hline Treatment & Concentration $(\mu \mathrm{g} / \mathrm{ml})$ & Relative luminescent units ${ }^{\mathrm{a}}$ & P-value & Inhibition $(\%$ control $)$ \\
\hline Control & - & $0.65 \pm 0.02$ & - \\
PC & 3 & $0.45 \pm 0.01$ & 0.020 & -30.8 \\
& 6 & $0.21 \pm 0.01$ & 0.014 & -72.3 \\
& 12 & $0.18 \pm 0.02$ & 0.001 & -84.8 \\
\hline
\end{tabular}

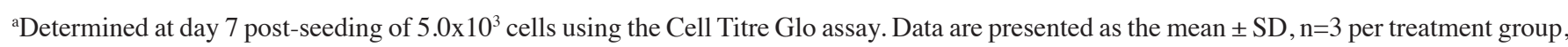
and analyzed by ANOVA and Dunnett's multiple comparison post-hoc test $(\alpha=0.05)$. PC, Psoralia corylifolia; ANOVA, analysis of variance.

Table III. Inhibition of anchorage-independent growth of MDA-MB-231 cells by PC.

\begin{tabular}{|c|c|c|c|c|}
\hline Treatment & Concentration $(\mu \mathrm{g} / \mathrm{ml})$ & AI colony number ${ }^{\mathrm{a}}$ & $\mathrm{IC}$ & P-value \\
\hline Control & - & $745 \pm 51$ & - & - \\
\hline \multirow[t]{7}{*}{$\mathrm{PC}$} & 1 & $641 \pm 59$ & & \\
\hline & 5 & $559 \pm 56$ & $\mathrm{IC}_{25}$ & 0.050 \\
\hline & 10 & $373 \pm 48$ & $\mathrm{IC}_{50}$ & 0.037 \\
\hline & 20 & $307 \pm 74$ & & \\
\hline & 40 & $230 \pm 58$ & & \\
\hline & 60 & $123 \pm 11$ & & \\
\hline & 80 & $69 \pm 5$ & $\mathrm{IC}_{90}$ & 0.014 \\
\hline
\end{tabular}

${ }^{\mathrm{a}} \mathrm{AI}$ colony number determined at day 21 post-seeding of $5.0 \times 10^{5}$ cells. Data are presented as the mean $\pm \mathrm{SD}, \mathrm{n}=3$ per treatment group, and analyzed by ANOVA with Dunnett's multiple comparison post-hoc test $(\alpha=0.05)$. AI, anchorage independent; IC, inhibitory concentration; PC, Psoralia corylifolia; ANOVA, analysis of variance.

\section{Results}

Growth inhibitory effect of $P C$. The data on the growth inhibitory effects of PC are presented in Table II. These data exhibited a dose-dependent inhibitory response in MDA-MB-231 cells. As indicated by the RLU values, treatment with 6 , 12 and $24 \mu \mathrm{g} / \mathrm{ml} \mathrm{PC}$ for 7 days resulted in a decrease of $67.7 \%$ $(\mathrm{P}=0.020)$, in a decrease of $72.3 \%(\mathrm{P}=0.014)$ and in a decrease of $84.8 \%(\mathrm{P}=0.001)$, respectively, relative to the untreated control. These data identified the $\mathrm{IC}_{25}$ as $2.4 \pm 0.3 \mu \mathrm{g} / \mathrm{ml}$, the $\mathrm{IC}_{50}$ as $4.4 \pm 1.0 \mu \mathrm{g} / \mathrm{ml}$ and the $\mathrm{IC}_{90}$ as $25.5 \pm 1.8 \mu \mathrm{g} / \mathrm{ml}$, respectively, relative to the untreated control.

Effect of PC on AI colony formation. The data on inhibition of AI colony formation by PC are presented in Tables III and SI. A 21-day treatment with PC identified the $\mathrm{IC}_{25}$ as $5 \mu \mathrm{g}(\mathrm{P}=0.050)$, 
Table IV. Effect of PC on cell cycle progression in MDA-MB-231 cells.

\begin{tabular}{lcccc}
\hline Treatment & Concentration $(\mu \mathrm{g} / \mathrm{ml})$ & $\mathrm{G}_{1}: \mathrm{S}+\mathrm{G}_{2} / \mathrm{M}^{\mathrm{a}}$ & P-value & Fold of control \\
\hline Control & - & $0.6 \pm 0.1$ & & \\
PC & 3 & $0.9 \pm 0.2$ & 0.020 & $2.5 \mathrm{x}$ \\
& 6 & $2.1 \pm 0.3$ & 0.014 & $3.5 \mathrm{x}$ \\
\hline
\end{tabular}

${ }^{a}$ Determined at day 3 post-seeding of $5.0 \times 10^{3}$ cells. Data are presented as the mean $\pm \mathrm{SD}, \mathrm{n}=3$ per treatment group, and analyzed by ANOVA with Dunnett's multiple comparison post-hoc test $(\alpha=0.05)$. PC, Psoralia corylifolia; ANOVA, analysis of variance.

Table V. Effect of PC on the apoptosis of MDA-MB-231 cells.

\begin{tabular}{|c|c|c|c|c|c|}
\hline Treatment & Concentration $(\mu \mathrm{g} / \mathrm{ml})$ & $\operatorname{Sub} \mathrm{G}_{0}(\%)^{\mathrm{a}}$ & P-value & Caspase-3/7 activity (RLU) ${ }^{\mathrm{a}}$ & P-value \\
\hline Control & - & $5.0 \pm 1.2$ & & $0.5 \pm 0.1$ & \\
\hline \multirow[t]{3}{*}{$\mathrm{PC}$} & 3 & $18.0 \pm 1.4$ & 0.020 & $6.5 \pm 1.3$ & 0.014 \\
\hline & 6 & $20.0 \pm 2.7$ & 0.020 & $50.8 \pm 3.1$ & 0.005 \\
\hline & 12 & $60.0 \pm 5.0$ & 0.014 & $75.0 \pm 5.0$ & 0.001 \\
\hline
\end{tabular}

a Determined at day 3 post-seeding of $5.0 \times 10^{4}$ cells. Data are presented as the mean $\pm \mathrm{SD}, \mathrm{n}=3$ per treatment group, and analyzed by ANOVA with Dunnett's multiple comparison post-hoc test $(\alpha=0.05)$. PC, Psoralia corylifolia; RLU, relative luminescent units; ANOVA, analysis of variance.

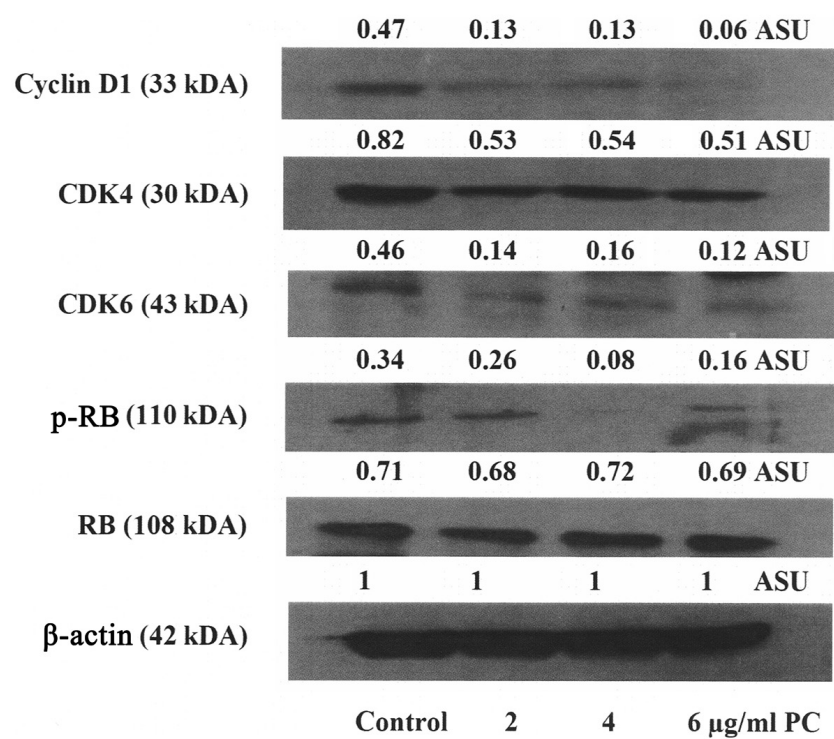

Figure 1. Western blot analysis of select proteins of the RB pathway. The expression levels of cyclin D1, CDK4, CDK6 and p-RB were inhibited in response to treatment with PC. PC, Psoralea corylifolia; CDK4, cyclin dependent kinase 4; CDK6, cyclin dependent kinase 6, p-RB, phosphorylated retinoblastoma; RB, retinoblastoma; ASU; arbitrary scanning unit.

the $\mathrm{IC}_{50}$ as $10 \mu \mathrm{g}(\mathrm{P}=0.037)$ and the $\mathrm{IC}_{90}$ as $80 \mu \mathrm{g}(\mathrm{P}=0.014)$, respectively, relative to the untreated control.

Effect of PC on cell cycle progression. The effect of PC on cell cycle progression is presented in Tables IV, SII and SIII. The data expressed as the $\mathrm{G}_{1}: \mathrm{S}+\mathrm{G}_{2} / \mathrm{M}$ ratio demonstrated that treatment with $\mathrm{PC}$ at $6 \mu \mathrm{g} / \mathrm{ml}$ exhibited a 2.5 -fold increase
$(\mathrm{P}=0.020)$ and treatment with $\mathrm{PC}$ at $12 \mu \mathrm{g} / \mathrm{ml}$ exhibited a 3.5 -fold $(\mathrm{P}=0.014)$ increase respectively, relative to the untreated control.

Effect of PC on RB signaling. The data presented in Fig. 1 are the results of the analyses of the effects of $\mathrm{PC}$ on the $\mathrm{RB}$ signaling. The proteins, cyclin D1, CDK4, CDK6 and p-RB, involved in this pathway exhibited a dose-dependent decrease, relative to the untreated control.

Effect of PC on cellular apoptosis. The data presented in Tables V and SIV are the results of the analyses of the effect of PC on cellular apoptosis by quantifying the status of cells in sub $\mathrm{G}_{0}$ (apoptotic) phase of the cell cycle and the pro-apoptotic caspase-3/7 activity. Treatment with $\mathrm{PC}$ resulted in a dose-dependent increase in the sub $\mathrm{G}_{0}$ phase, as well as an increase in the caspase activity, relative to the untreated control.

\section{Discussion}

Conventional treatment options for TNBC are frequently associated with systemic toxicity and acquired drug resistance leading to progression of therapy resistant disease. Moreover, there are no drugs available for secondary prevention of TNBC. These considerations emphasize a need to identify relatively non-toxic efficacious naturally occurring testable alternatives. The nutritional herb, $\mathrm{PC}$, has documented anti-oxidative, chemo-protective and anti-inflammatory activities. This herb is used in the traditional Chinese medicine and in Indian Ayurvedic medicine for general health management, as a treatment for leukoderma and 
psoriasis, and also as a palliative for breast cancer patients. PC is commonly used in a dose range of 10 to $15 \mathrm{~g}$ in herbal formulations in combination with additional herbs (14).

In the present study, treatment of the MDA-MB-231 cells with PC at a low concentration range of 3 to $24 \mu \mathrm{g} / \mathrm{ml}$ led to a dose-dependent reduction in viable cell number, identifying an effective dose range of 3 to $12 \mu \mathrm{g} / \mathrm{ml}$, and a maximum cytostatic dose of $24 \mu \mathrm{g} / \mathrm{ml}$.

Experiments using the anchorage-independent colony formation assay revealed a dose-dependent reduction in the number of AI colonies in response to treatment with PC. Published evidence on the present TNBC model has demonstrated quantifiable increase in AI colony number $(9,10)$. By contrast, the triple-negative non-tumorigenic 184-B5 breast epithelial cells are notable for the absence of AI colony formation (15). The selectivity of AI growth in the carcinoma derived cells suggests that the AI colony formation represents a sensitive and specific in vitro surrogate end point biomarker for in vivo tumorigenic potential. Thus, the inhibition of AI colonies in response to treatment with PC suggests that PC may reduce the risk of developing breast cancer.

In the present study, experiments to examine the effects of PC on cell cycle progression revealed an increased $\mathrm{G}_{1}: \mathrm{S}+\mathrm{G}_{2} / \mathrm{M}$ ratio due to $G_{1}$ phase arrest. At the mechanistic level, the inhibition of cell cycle progression was associated with reduced expression levels of cyclin D1, CDK4, CDK6 and p-RB. TNBC is notable for defective RB signaling pathway, and cyclin D1 is involved in the CDK4/CDK6 ${ }^{-} \mathrm{pRB}$ pathway (16). Cyclin D1 functions as a $G_{1}$ specific cyclin for $G_{1}$ to $S$ phase transition during cell cycle progression, and represents a potential therapeutic target (17). Pharmacological inhibitors of CDK4 and CDK6 function during $G_{1}$ to $S$ phase transition (18). Thus, the data demonstrating that $P C$ induced $G_{1}$ arrest, and inhibited CDK4 and CDK6 expression, suggest that PC may function as a natural $\mathrm{CDK}$ inhibitor. Collectively, these data suggest that PC may downregulate defective RB signaling and thereby, provide plausible mechanistic leads for the anti-proliferative effects of $\mathrm{PC}$ in the present experimental system.

Experiments to examine the effect of $\mathrm{PC}$ on cellular apoptosis revealed that treatment with $\mathrm{PC}$ at the concentration range of 3 to $12 \mu \mathrm{g} / \mathrm{ml}$ induced an increase in the $\mathrm{subG}_{0}$ (apoptotic) phase of the cell cycle, and a corresponding increase in the pro-apoptotic caspase-3/7 activity. Collectively, these data provide a mechanistic lead for pro-apoptotic effects of PC and suggest possible involvement of the intrinsic pathway of cellular apoptosis.

Traditional Chinese medicine involves boiling the herbal formulation to prepare an aqueous extract for patient consumption. To simulate this clinical scenario, a non-fractionated aqueous extract of PC was used in the present study. The specific role of individual bioactive components in the herbal formulation is not well-defined. It is conceivable that the bioactive agents may act in a synergistic/additive manner, leading to growth inhibitory efficacy. The phytochemical analysis of PC has demonstrated the presence of coumarins, flavonoids and meroterpenes (19). The phytochemical isobavachalcone present in $\mathrm{PC}$ has been documented to increase ER- $\alpha$ expression, CD44 expression and affects paclitaxel resistance in MCF-7 breast cancer cells (20). In colon carcinoma-derived HCT-116 and SW480 cells, this phytochemical has documented efficacy via the AKT/GSK-3 $\beta / \beta$-catenin axis (21), and has also been shown to inhibit cyclin D1 and CDK-4 in HCT116, SW480, LoVo and HT29 colon carcinoma-derived cellular models (22). The anti-proliferative and pro-apoptotic effects of PC extract in the MCF-7 model have been shown to be due to the upregulation of PARP, reactive oxygen species (ROS), pro-apoptotic caspase-7, caspase-9 and BCl-2 associated protein X (BAX), respectively (23). Psoralen, another putative bioactive agent present in $P C$, has been shown to induce $G_{1}$ arrest and reverse the expression of multi-drug resistance (MDR) genes in an adriamycin-resistant MCF-7/ADR model (24). Taken together, these mechanistic data provide a proof of concept for involvement of select cell cycle regulatory and apoptosis specific proteins in the growth inhibitory effects of PC.

At the present time, no drugs are available for the secondary prevention of TNBC, at least to the best of our knowledge. Since PC has demonstrated efficacy against TNBC and is a non-toxic nutritional herb, it carries great promise for effective long-term secondary prevention for this type of breast cancer.

In conclusion, the present study provides plausible mechanistic leads for the efficacy of PC as a testable alternative against TNBC. Furthermore, these in vitro data on a cellular model of TNBC represent a scientific rationale for subsequent in vivo investigations on TNBC tumors. Overall, the study outcome validates the present experimental approach to identify and prioritize efficacious natural products as potential dietary supplements for prevention/therapy of breast cancer.

\section{Acknowledgements}

Not applicable.

\section{Funding}

Major funding for the present study was provided by philanthropic contributions to the American Foundation of Chinese Medicine from the Randall and Barbara Smith Foundation, and the Sophie Stenbeck Family Foundation.

\section{Availability of data and materials}

The datasets used and/or analyzed during the current study are available from the corresponding author on reasonable request.

\section{Authors' contributions}

NTT conceived the study design, formulated the experimental protocols and prepared the manuscript. HBN conducted the experiments, organized and analyzed the data and participated in the preparation of the manuscript. GYCW selected the nutritional herb for the study and contributed to the data interpretation and preparation of the manuscript.

\section{Ethics approval and consent to participate}

Not applicable.

\section{Patient consent for publication}

Not applicable. 


\section{Competing interests}

The authors declare that they have no competing interests.

\section{References}

1. Dinh P, Sotiriou C and Piccart MJ: The evolution of treatment strategies: Aiming at the target. Breast 16 (Suppl 2): S10-S16, 2007.

2. Anders CK, Winer EP, Ford JM, Dent R, Silver DP, Sledge GW and Carey LA: Poly(ADP-Ribose) polymerase inhibition: 'targeted' therapy for triple-negative breast cancer. Clin Cancer Res 16: 4702-4710, 2010.

3. Ibrahim YH, García-García C, Serra V, He L, Torres-Lockhart K, Prat A, Anton P, Cozar P, Guzmán M, Grueso J, et al: PI3K inhibition impairs BRCA1/2 expression and sensitizes BRCA-proficient triple-negative breast cancer to PARP inhibition. Cancer Discov 2: 1036-1047, 2012.

4. Dean M, Fojo T and Bates S: Tumour stem cells and drug resistance. Nat Rev Cancer 5: 275-284, 2005

5. Neergheen VS, Bahorun T, Taylor EW, Jen LS and Aruoma OI: Targeting specific cell signaling transduction pathways by dietary and medicinal phytochemicals in cancer chemo-prevention. Toxicology 278: 229-241, 2010.

6. Ye L, Jia Y, Ji KE, Sanders AJ, Xue K, Ji J, Mason MD and Jiang WG: Traditional Chinese medicine in the prevention and treatment of cancer and cancer metastasis. Oncol Lett 10 1240-1250, 2015.

7. Telang N, Li G, Katdare M, Sepkovic D, Bradlow L and Wong G: Inhibitory effects of Chinese nutritional herbs in isogenic breast carcinoma cells with modulated estrogen receptor function. Oncol Lett 12: 3949-3957, 2016.

8. Telang NT, Li G, Katdare M, Sepkovic DW, Bradlow HL and Wong GYC: The nutritional herb Epimedium grandiflorum inhibits the growth in a model for the Luminal A molecular subtype of breast cancer. Oncol Lett 13: 2477-2482, 2017.

9. Telang N, Nair HB and Wong GYC: Efficacy of Dipsacus asperoides (DA) in a model for triple negative breast cancer. Cancer Res 77 (Suppl 4): Abstract nr P4-13-04, 2017.

10. Telang NT, Nair HB and Wong GYC: Growth inhibitory efficacy of Cornus officinalis in a cell culture model for triple-negative breast cancer. Oncol Lett 17: 5261-5266, 2019.

11. Bosco EE and Knudsen ES: RB in breast cancer: At the crossroads of tumorigenesis and treatment. Cell Cycle 6: 667-671, 2007.

12. Neve RM, Chin K, Fridlyand J, Yeh J, Baehner FL, Fevr T, Clark L, Bayani N, Coppe J-P, Tong F, et al: A collection of breast cancer cell lines for the study of functionally distinct cancer subtypes. Cancer Cell 10: 515-527, 2006.
13. Subik K, Lee JF, Baxter L, Strzepek T, Costello D, Crowley P, Xing L, Hung MC, Bonfiglio T, Hicks DG, et al: The expression patterns of ER, PR, HER-2, CK5/6, EGFR, Ki 67, and AR by immune-histochemical analysis in breast cancer cell lines. Breast Cancer (Auckl) 4: 35-41, 2010. Erratum in: Breast Cancer (Auckl) 12: 1178223418806626, 2018.

14. Khushboo PS, Jadhav VM, Kadam VJ and Sathe NS: Psoralea corylifolia Linn. - 'Kushtanashini'. Pharmacogn Rev 4: 69-76, 2010.

15. Telang N: Anti-proliferative and pro-apoptotic effects of rosemary and constituent terpenoids in a model for the HER-2-enriched molecular subtype of clinical breast cancer. Oncol Lett 16: 5489-5497, 2018.

16. Burkhart DL and Sage J: Cellular mechanisms of tumour suppression by the retinoblastoma gene. Nat Rev Cancer 8: 671-682, 2008.

17. Musgrove EA, Caldon CE, Barraclough J, Stone A and Sutherland RL: Cyclin D as a therapeutic target in cancer. Nat Rev Cancer 11: 558-572, 2011.

18. Sherr CJ and Roberts JM: CDK inhibitors: Positive and negative regulators of G1-phase progression. Genes Dev 13: 1501-1512, 1999.

19. Zhang X, Zhao W, Wang Y, Lu J and Chen X: The chemical constituents and bioactivities of Psoralia corylifolia Linn.: A Review. Am J Chin Med 44: 35-60, 2016.

20. Shi J, Chen Y, Chen W, Tang C, Zhang H, Chen Y, Yang X, Xu Z, Wei J and Chen J: Isobavachalcone sensitizes cells to E2-induced paclitaxel resistance by down-regulating CD44 expression in ER+ breast cancer cells. J Cell Mol Med 22: 5220-5230, 2018

21. Li Y, Qin X, Li P, Zhang H, Lin T, Miao Z and Ma S: Isobavachalcone isolated from Psoralia corylifolia inhibits cell proliferation and induces apoptosis via inhibiting AKT/GSK-3 $\beta /$ $\beta$-catenin pathway. Drug Des Devel Ther 13: 1449-1460, 2019.

22. Park GH, Sung JH, Song HM and Jeong JB: Anti-cancer activity of Psoralea fructus through the downregulation of cyclin D1 and CDK4 in human colorectal cancer cells. BMC Complement Altern Med 16: 373, 2016.

23. Rajan V, Tripathi J, Variyar P and Pandey BN: Mechanism of cytotoxicity by Psoralea corylifolia extract in human breast carcinoma cells. J Environ Pathol Toxicol Oncol 33: 265-277, 2014.

24. Wang X, Cheng K, Han Y, Zhang G, Dong J, Cui Y and Yang Z: Effect of Psoralen as an anti-tumor agent in human breast cancer MCF-7/ADR cells. Biol Pharm Bull 39: 815-822, 2016.

This work is licensed under a Creative Commons Attribution-NonCommercial-NoDerivatives 4.0 International (CC BY-NC-ND 4.0) License. 